\title{
Forest Cover Assessment in Tuv province of Mongolia Using MODIS and Landsat-7 ETM+
}

\author{
RTsolmon*, KYanagida **, M. Erdenetuya*** and L. Ochirhuyag ${ }^{* * *}$ \\ * National University of Mongolia \\ ** Japan Ecology Foundation Minato-Ku, Tokyo 106-0032, Japan \\ *** National Remote Sensing Center Mongolia
}

\begin{abstract}
The study aimed at determining the relative proportions of forest cover and other components in a mixed pixel. For this purpose a linear mixing model was used for the derivation of a land cover classification map in two study areas of Tuv province, Mongolia. Main types of forest cover change are forests to burn scars and agricultural fields in the study areas. In this paper, two reflective channels 3 and 4 of LANDSAT ETM+ and reflective channels land 2 of MODIS data was used to map five and four land components respectively. Clouds proportion was derived using MODIS data. A synergy between high-resolution MODIS and Landsat ETM+ data may greatly enhance the operational success of satellite based vegetation monitoring, in providing multi-spectral data on parameters of the environment.
\end{abstract}

\section{Introduction}

Only $8.1 \%$ of Mongolia is forested. The forest area will decrease due to expansion of the steppe and desert zones. The total biomass of all forests of Mongolia decreased by 27.2\%. (Mongolian Nature Environment-2001).

To obtain knowledge of how forest is scattered within countries, it is necessary to use remotely sensed data. Another problem is leak of tools and methods to manage and monitor the forest in a large area. The linear mixing model previously developed is applied to two study areas to generate regional estimates of forest and other land components over Tuv province Mongolia. The forests play a crucial role in these areas. Main types of forest cover change in the study areas are conversions between forest and non-forest, forest to burn scars, forests to agricultural fields and conversion of temperate mixed woodland to commercial.

Recently, remote sensing technology has been an efficient and helpful tool to monitor forest and plantation in large area. Remote sensing technology has capability to monitor and understand how existing land cover areas are presented on the ground especially for the forest cover estimation in the study areas. This indicates that identification and mapping forest cover are important to manage actual information about forestry in developing countries such as in Mongolia.

\section{Study area and data}

\subsection{Study area description}

Two study areas were selected for the analyses in this paper. The first study 
area is located between $49^{\circ} 32^{\prime}$ to $49^{\circ} 54^{\prime} \mathrm{N}$ and $107^{\circ} 15^{\prime}$ to $107^{\circ} 59^{\prime} \mathrm{E}$ in northern part of Tuv province Mongolia^ consisting of forest areas which have been heavily logged and damaged from repeated fires. The area consisted of a managed forest reserve, surrounded by a mosaic of steppe and agro-forestry. The second area, is located in the central part of Tuv province Mongolia, within 48-50 N and $106^{\circ} 00^{\prime}$ $108^{\circ} 00^{\prime \prime} \mathrm{E}$. The area allocated for reforestation is approximately 700.6 hectares, which includes herbaceous species and agricultural land and is an example of a temperate mixed forest. In both of 2 study areas annual precipitation is 200$250 \mathrm{~mm}$. The forest type in these areas is mountain Taiga which forms East Siberian taiga and Khentii mointain zones. The dominant forests are Larix sibirica, pinus sylvestris, Pinus sibirica, Picea obovata, Abies sibirica, Betula. The complex character of vegetation cover structure explains the highest characteristics of biodiversity here: combinations of ecosystems of different types (mountain -tundra, mountain-forest, mountain-steppe). Vegetation presented by more than 1000 species. Rhododendron danuricum, Spirea media, Vaccinium vitisdaea, Dasiphora frutiicosa are mainly vegetation. Every year harmful different insects causes negative affects to forests. For instance, most dangerous insects such as Siberian Jacobson's Cankerworm, Gispy Moth and others (Oyundar 2001). These detailed analysis have been made from the forest inventories by Forestry department of Mongolian National University since 1992 year.

\subsection{Data}

The MODIS is one of the few space -borne sensors currently capable of acquiring radiometric data over the range of view angles. However, the relatively coarse spatial resolution of the MODIS often results in measurements of mixed land covers. On the other hand, Landsat ETM can give us the detailed land cover information with high spatial resolution $(30 \mathrm{~m})$.

A cloud free portion of the Landsat Enhanced Thematic Mapper -Plus (ETM+) data, acquired on 19 August 2000 at pixel size $30 \mathrm{~m}$, was selected for the analysis in the first study area. Moderate Resolution Imaging Spectroradiometer (MODIS) of the scene 250m product of NASA's Earth Observation System recorded on 25 August 2000 was used for the second study area.

\section{Method}

Many quantitative validations of global land cover products is very challenging due to the absence of reliable reference datasets, particularly in the case of proportion land coverage. A suitable way of extracting information from such scenes is to estimate how each ground pixel's area is divided up among different land cover types. This approach is usually known as Mixture Modeling, with limited amount of works devoted to the subject in remote sensing literature. Several techniques (Smith et al. 1985, Shimabukuro 1987) to solve the mixture problem have been applied to a number of fine spatial resolution data sets from Multispectral Scanner System 
(MSS); Thematic Mapper (TM) data (Adams and Adams 1984, Shimabukuro 1987); and AVIRIS (Airborne Visible/Infrared Imaging Spectrometer) data (Gillespie et al.1990). The first four AVHRR channels were used by Cross et al. (1991) to differentiate tropical forest from non-forest, with satisfactory results compared with ETM+ images. This research applied a technique linear mixing model is based on Optimization Methods (Tsolmon 2000) to ETM+ and MODIS to generate fraction images. The basic concept of the spectral Linear Mixing Model can be expressed in Equation lit estimates the proportion of each component in a pixel by minimizing the sum of squares of errors (equation 2) with constraints (equation3)

The basic mixture model (1)

uses the Constrained Least Squares Method which estimates the proportion of each component in a pixel by minimizing the sum of squares of errors (2) with constraint (3)

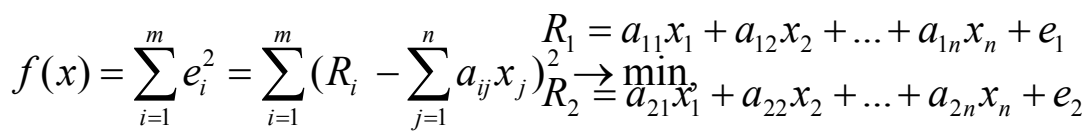

subject to:

$$
\begin{aligned}
& x_{1}+x_{2}+x_{3}+\ldots x_{n}=1, \quad R_{m}=a_{m 1} x_{1}+a_{m 2} x_{2}+\ldots+a_{m n} x_{n}+e_{m} \\
& x_{1} \geq 0, x_{2} \geq 0, x_{3} \geq 0 \ldots x_{n} \geq 0,
\end{aligned}
$$

where $R_{i}$ is measured satellite sensor response for a pixel in spectral band $i$ $a_{i j}$ is spectral response of mixture component, j, for spectral band i. Results of numerical method were used for the mapping of fraction images.

\section{Approach}

The linear mixture model based on Optimization Method using Constrained Least Squares Method (Tsolmon 2003) was applied to the regional scales using ETM+ and MODIS data acquired on 19 August 2000 and 25 Aug 2000, respectively. In the former dataset, only ETM channel $3(0.63-0.69 \mu \mathrm{m})$ and channel 4 (0.76-0.90 $\mu \mathrm{m})$ were available, while in the latter, MODIS channels red $(620-670 \mathrm{~nm})$ and MR (841-876nm) were used. The five components defined for the ETM data are namely: pine, larch, agriculture land grassland and bare soil classes. Likewise, four 
components were defined for the MODIS dataset, namely: Pine, Larch, grass, clouds. Fraction images were subsequently derived for these image datasets.

In order to examine the validity of the results the fraction images (Figure 1) from 19 August, 2000 ETM+ were compared with the false color composite image (Figure 2 AXRGB=bands $4,3,1$ ) visually and compared with the classified Landsat ETM+ data using a Maximum likelihood supervised classification (Figure 2 B) for the model validation. There was a visual similarity of vegetation fraction images with the ETM+ false color composite image.

The derived fraction images from MODIS (Figure 3) were compared with the supervised classified MODIS image using a Maximum likelihood supervised classification (Figure $4 \mathrm{~A}$ ) data and were further validated with raw image (Figure 4 $B$ ) visually. A visual inspection of Figure 4 B shows that the assumptions of the study are nearly true.

Confusion matrices were used to validate the accuracy of the method. Accuracies were determined empirically, by selecting samples of pixels from the thematic map and checking their labels against classes determined from reference data image for both the sites, (i.e. verified through ground truth previously by International Expedition 2000 Selenge basin and Ground truth data were collected in August, 2000 by Forestry Department , National University Mongolia and maps of scale 1:500,000 (National Map of Mongolia 1990), 1:100,0000 (Sheet number M-48 Ecosystems of Mongolia 1995; The reference images used for this study were classified ETM+ and MODIS images which have overall classification accuracies of $\mathbf{8 7 . 4 4 \%}$ and $88.25 \%$ respectively.

Stratified random sampling was chosen as the sampling method for accuracy assessment. The approach provided better statistical significance since it avoided correlated near-neighboring pixels. A total of 202 and 203 random sampling sites were made on both ETM+ and MODIS fraction images. The overall classification accuracies are $92.57 \%$ (Table 1 ) and $80.78 \%$ (Table 2) for the ETM+ and MODIS fraction images, respectively, and were achieved by taking the average of the percentages of correct classifications.

\section{Results and Discussion}

Classification results indicate that pine can be classified with an acceptable accuracy. The forest fraction image seems to be useful for forest biomass studies since it contains cover percentage information about forest proportion within the pixels. The combined use of LANDSAT-7 ETM+ and MODIS data allows users to have access to monitor important vegetation resources and estimating net primary productivity of northern ecosystems (grassland, boreal forest). The procedure produced proportion maps showing the percentage of components within pixel size of 30 meters and $250 \mathrm{~m}$ (for TM and MODIS). The output fraction images were compared with the supervised classification images derived from TM and MODIS. Application of the method to higher resolution data to test its potential was hindered 
in this study, by lack of multi-temporal, high-resolution data sets. Further work should test the robustness of the approach adopted here, when applied to large areas by using multi-temporal data to detect environmental changes resulting from anthropogenic activity. The main problem in monitoring was cloudy condition. The study had considered not only the forest cover components but also cloud as cover components. The advantage of fraction images is that they contain physical information such as amount of each component within the pixel such as cloud. Further work must be done to tune the procedure with cloud free images and compare with cloud portion image.

\section{Acknowledgments}

The authors are grateful to EOS Data Center of NASA for supplying the MODIS data. We also would like to thank Dr. Batchuluun and members from Forestry Department Biological Faculty from Mongolian National University for their assistance in collecting ground truth data. 


\section{References}

Adams,J.B.,and Adams, J.D.,1984, Geologic mapping using Landsat MSS and TM images:removing vegetation by modeling spectral mixtures.Proceedings of the Third Thematic Conference on Remote Sensing for Experimental Geology,Colorado Springs,Colorado,(Michigan:ERIM), pp.615-622.

Cross, A.M., Settle, J.J., Drake, N.A., and Paivinen, R.T.M., 1991, Subpixel measurement of tropical forest cover using AVHRR data. International Journal of Remote Sensing, 6, 1159-1177.

Gillespie, A.R.,Smim,M.O.,Adams,J.B.,Willis,S.C.,Fischer,A.F.ffl,and Sabol,D.E., 1990, Interpretation of residuals images: spectral mixture analysis of AVIRIS images, Owens Valley, California. Proceedings of the Airborne Science Workshop: AVIRIS, JPL, Pasadena,CA, (JPL Publication 90-54),pp.243-270.

Shimabukuro, Y. E., Holben, B. N., and Tucker, C. J., 1994, Fraction images derived from NOAAAVHRR data for studying the deforestation of the Brazilian Amazon. International Journal of Remote Sensing, 15,517-520.

Smith,M.O.,Johnson, P.E., and Adams, J.B., 1985, Quantitative determination of mineral types and abundances from reflectance spectra using principal component analysis. Journal of Geophysical Research,90,792-804.

Shimabukuro, Y.E., 1987, Shade images derived from linear mixing models of multispectral measurements of forested areas. Ph.D. Dissertation, Colorado State University, Fort Collins, CO.

Tsolmon R., R. Tateishi "A Linear mixture model for land cover classification using $8 \mathrm{~km}$ and $\mathrm{lkm}$ AVHRR data," Proceeding of Japan Society of Photogrammetry and Remote Sensing Symposium, Japan, pp.213-216,17 November 2000 (Tottori: JSPRS).

Tsolmon, R., 2003 , Methodology to estimate coverage and biomass of boreal forests using satellite data. Doctoral Dissertation, Chiba University, Chiba, Japan. 


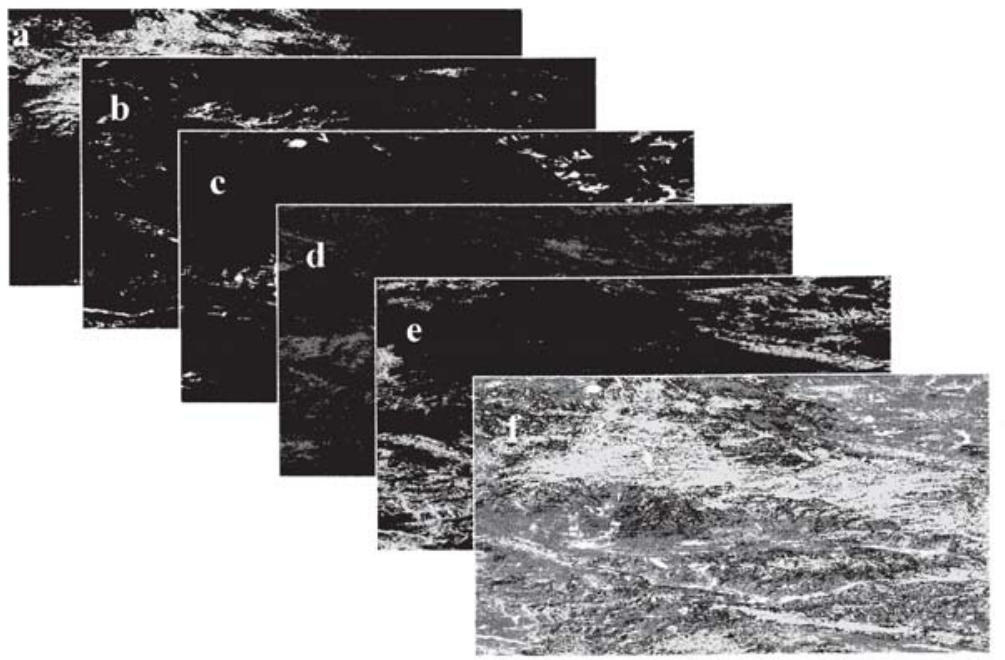

Figure 1 Fraction images derived from Landsat ETM+ data acquired on 19 August, 2000 for components $\mathrm{a}=$ pine, $\mathrm{b}=$ larch, $\mathrm{c}=$ agriculture, $\mathrm{d}=$ grassland, $\mathrm{e}=$ bare soil and $\mathrm{f}=$ composite of fraction images obtained by linear mixing model. 
A

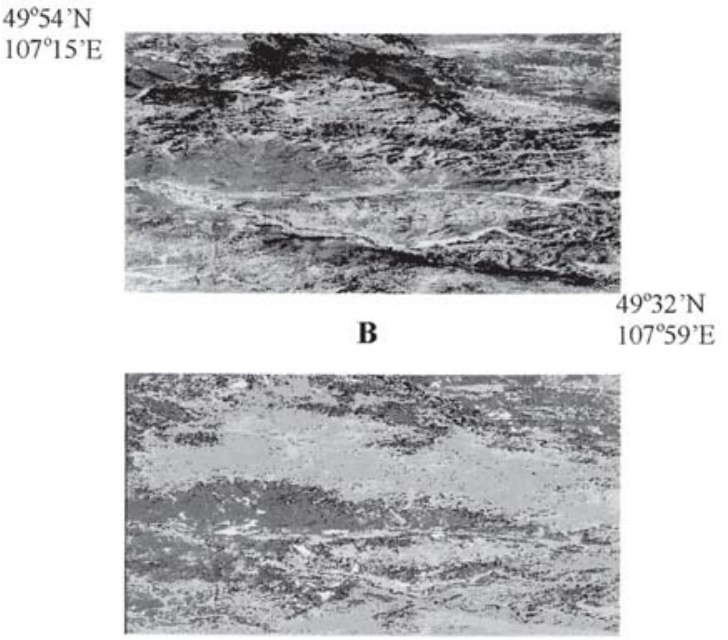

Figure $2 \mathrm{~A}$ is false color composites (RGB=bands 4,3,1),

B is Supervised classification respectively from ETM+ image acquired on 19 August, 2000

(Green $=$ pine, blue $=$ larch, pink $=$ agriculture, brown $=$ grassland and yellow $=$ bare soil 
A

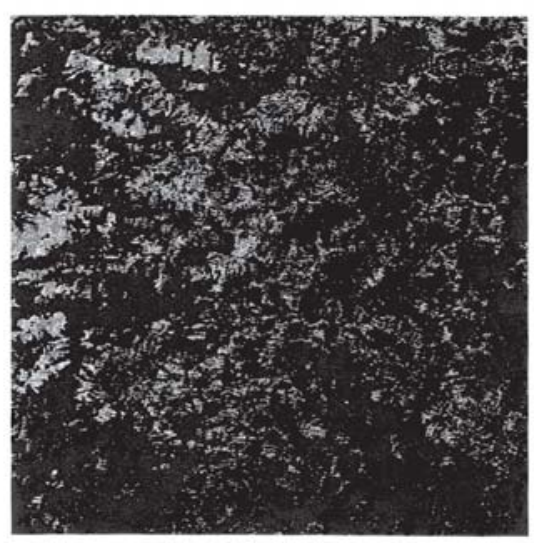

C

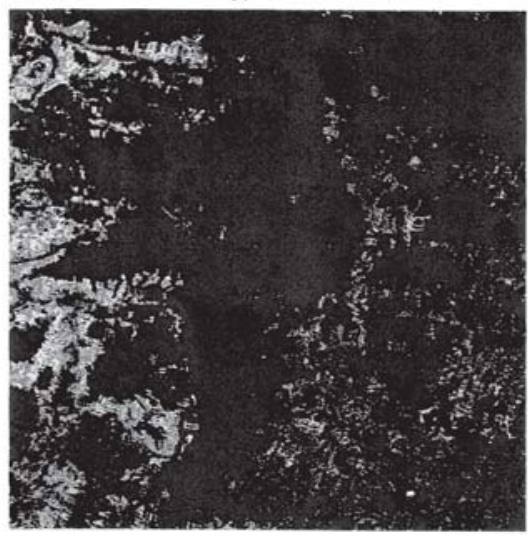

B

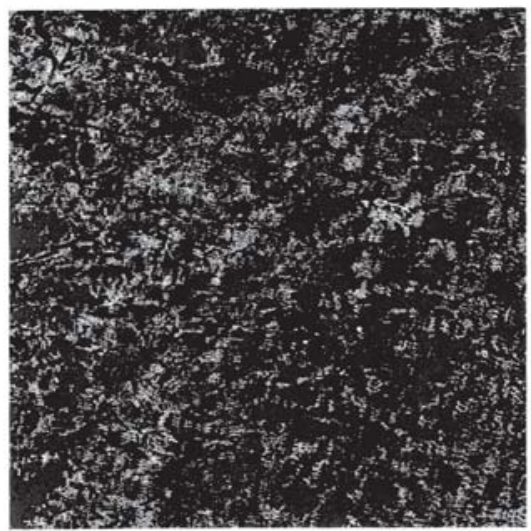

D
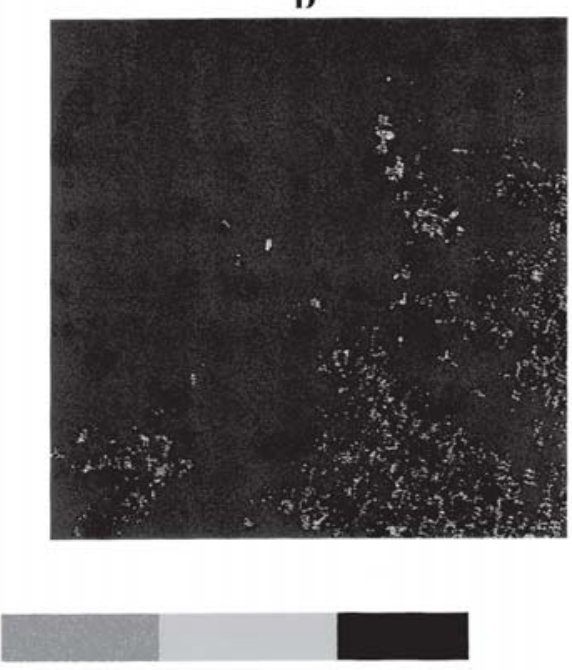

$45 \%$

$60 \%$

$75 \%$

Figure 3 Fraction images derived from MODIS data acquired on 25 August, 2000 for components $\mathrm{A}=$ pine, $\mathrm{B}=$ larch, $\mathrm{C}=$ grassland and $\mathrm{D}=$ cloud obtained by linear mixing model. 


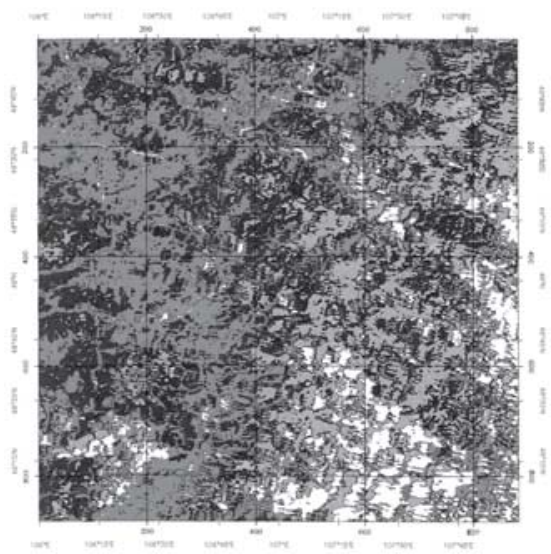

B

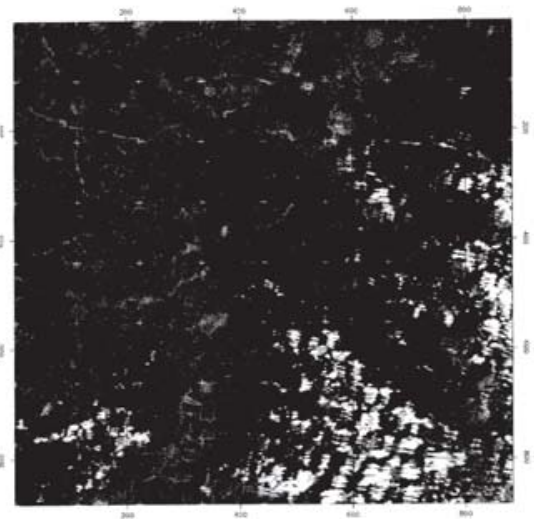

Figure 4: $\mathrm{A}$ is supervised classification (green is pine, pink is larch blue is grass, white is cloud) and B is Raw image from MODIS image acquired on 25 August, 2000 . 